\title{
Semen characteristics and testosterone profiles in ferrets kept in a long-day photoperiod, and the influence of hCG timing and sperm dilution medium on pregnancy rate after laparoscopic insemination
}

\author{
D. E. Wildt, M. Bush, C. Morton*, F. Morton* and J. G. Howard \\ National Zoological Park, Smithsonian Institution, Washington, DC 20008, USA; and \\ *Path Valley Farm, Willow Hill, PA 17271, USA
}

\begin{abstract}
Summary. Five domestic ferrets previously maintained for 12 weeks under a 16L:8D photoperiod were electroejaculated weekly for 15-65 weeks while continuing to be exposed to the prolonged light cycle. Two ferrets sustained spermatogenesis for 20 and 26 weeks, while sperm production in the remaining males either was sporadic or decreased, remained depressed and then increased to peak levels observed in other males. Regardless of the temporal spermatogenesis patterns within males, the number of electroejaculated spermatozoa with residual cytoplasmic droplets or abnormal acrosomes increased in all ferrets over time. Diluted ejaculates meeting artificial insemination criteria were deposited intravaginally or by transabdominal laparoscopy into the uterine horns of females treated 0 or $24 \mathrm{~h}$ earlier with 90 i.u. hCG. Vaginal insemination was ineffective ( 0 pregnancies in 10 attempts), but $17 / 24$ ferrets $(70 \cdot 8 \%)$ inseminated laparoscopically became pregnant and delivered live young (mean litter size, $5.2 \mathrm{kits})$. Number of motile spermatozoa deposited in utero (1.6-10.0 $\times 10^{6}$ cells), presence of glycerol in the sperm dilution medium $(0$ versus $4 \%)$ and time of hCG administration ( 0 versus $24 \mathrm{~h}$ before insemination) had no effect on pregnancy results or litter size.
\end{abstract}

Keywords: ferret; semen; electroejaculation; spermatozoa; artificial insemination; hCG

\section{Introduction}

The reproductive physiology of the domestic ferret (Mustela putorius furo) has been studied sporadically for more than 80 years. The ferret is valuable for studying ovulation and fertilization (Hammond \& Marshall, 1930; Chang, 1965), mammalian hybridization (Chang, 1968) and the neural mechanisms influencing reproductive seasonality (Baum \& Goldfoot, 1974; Herbert et al., 1978), hypothalamo-pituitary-gonadal function (Carroll et al., 1985, 1987; Sisk \& Dejardins, 1986; Sisk, 1987) and sexual maturation (Ryan, 1984; Ryan \& Robinson, 1987). We have used the domestic ferret for developing artificial breeding strategies for the black-footed ferret (Mustela nigripes), a species once widely distributed from the American southwest to the Canadian provinces of Saskatchewan and Alberta (Clark, 1987). Loss of habitat and eradication of prey reduced free-ranging populations and, from 1978 to 1981, the species was thought to be extinct. However, a small population was rediscovered in 1981 in Wyoming and, presently, there are 58 black-footed ferrets maintained by the state of Wyoming in a captive breeding programme. Although efforts have emphasized natural breeding of captive individuals, exploration of artificial breeding approaches by using non-endangered animals has been recommended (Black-Footed Ferret Recovery Plan, 1988). The domestic ferret and black-footed ferret are 
taxonomically in the same genus and recent molecular analyses indicate close genetic similarity (O’Brien et al., 1989).

Domestic ferrets are seasonal breeders with reproductive activity stimulated by a long-day photoperiod (Hammond \& Marshall, 1930; Bissonette, 1932, 1935; Donovan, 1967). In ferrets exposed to natural photoperiodic cues, testicular size gradually increases beginning in December or January, peaks from April through June and then gradually declines (Neal et al., 1977). The female's breeding season is characterized by changes in vaginal cytology and vulvar tumescence and generally is restricted to the months of April to August (Robinson, 1918; Hammond \& Marshall, 1930; Allanson, 1932). The domestic ferret is a reflex ovulator with ovulation occurring $\sim 30 \mathrm{~h}$ after a single copulation (Hammond \& Marshall, 1930; Hammond \& Walton, 1934) and 24. $36 \mathrm{~h}$ after an injection of human chorionic gonadotrophin (hCG) (Chang \& Yanagimachi, 1963; Chang, 1965).

The present study addressed issues of importance to the practical application of AI in ferrets including: (1) the ability to recover sequentially viable spermatozoa from males maintained under an artificially long photoperiod; (2) the comparative effectiveness of vaginal versus uterine insemination via a laparoscopic approach; and (3) the influence of sperm number, dilution medium and time of hCG administration on pregnancy rate, gestation interval and number of offspring produced.

\section{Materials and Methods}

Animals and experimental treatments. Five adult, proven breeder males (24-36 months of age; $1 \cdot 2-1 \cdot 5 \mathrm{~kg}$ body wt) served as semen donors and were maintained at the National Institutes of Health (NIH) Animal Center, Poolesville, MD, USA. Males were housed individually in a closed room $\left(21^{\circ} \mathrm{C}\right)$ in $91 \times 87 \times 79 \mathrm{~cm}$ (length $\times$ width $\times$ height) adjacent cages, each containing a nest box and a 60-W light bulb. Dry mink chow (Milk Specialities Co., Dundee, IL, USA) and water were provided daily. At the onset of the study, each male was considered to be in breeding condition based on testicular size. Each had been exposed to an artificial photoperiod of $16 \mathrm{~h} \mathrm{light} / 8 \mathrm{~h}$ dark for 12 weeks before study onset. This light cycle was continued throughout the study (lights turned on at 07:00 h daily) and there was no exposure to fluctuations in natural photoperiod or seasonal temperature.

Female ferrets $(\mathrm{N}=34,24-36$ months of age; $0.9-1.3 \mathrm{~kg}$ body wt) were maintained at Path Valley Farm (Willow Hill, PA, USA), $63 \mathrm{~km}$ from the NIH site. Before artificial breeding, females were housed together in groups of 3-4 and provided with the same diet as were males. All females previously had produced at least 1 litter within 6 months of Al. To induce oestrus, females were exposed continuously to a $16 \mathrm{~L}: 8 \mathrm{D}$ cycle and then monitored daily for vulvar tumescence. Females with maximal vulvar swelling were considered to be in oestrus and assigned to a study with 2 main treatment variables: (1) time of administration of hCG (Sigma Chemical Co., St Louis, MO, USA); and (2) semen dilution medium (designated TEST) with or without glycerol. The constituents of TEST were: $20 \%$ egg yolk, $4.8 \%$ Tes-n-Tres, $1.15 \%$ Tris, $0.4 \%$ glucose (Howard et al., 1986b) with or without $4 \%$ glycerol. The justification for examining the influence of glycerol was based on future studies planned to test the fertilizability of thawed ferret spermatozoa. Because glycerol is a common cryoprotectant for spermatozoa, it was important to determine whether the $4 \%$ level (presumed suitable for freezing ferret semen) affected sperm viability.

Females were injected with hCG $(90$ i.u., i.m.; Chang, 1965) at 1 of 2 times. Half the ferrets were treated at Path Valley Farm $24 \mathrm{~h}$ before scheduled AI and $22 \mathrm{~h}$ later crated and transported by vehicle to the NIH Animal Center where AI began $24 \mathrm{~h}$ after injection. The remaining females were transported similarly and received the same dosage of hCG but coincident with the onset of AI.

Semen collection and evaluation. Males were anaesthetized weekly with tiletamine-zolazepam (Telazol ${ }^{\circledR}:$ A. H. Robbins, Richmond, VA, USA; $13 \mathrm{mg} / \mathrm{kg}$, i.m.) for electroejaculation. Semen was collected from 1,1 and 2 ferrets for 50,55 and 65 consecutive weeks, respectively; 1 ferret, electroejaculated for 15 weeks, died unexpectedly from a liver complication unrelated to the study. The first electroejaculation of Males 1, 2 and 3 occurred on 18 November with the initial semen collection for Males 4 and 5 commencing on 10 March and 23 January, respectively. Because ferrets were exposed only to an artificial long-day photoperiod both before and throughout the study, natural seasonal effects on results were considered minimal. A surgical plane of anaesthesia was achieved within 3 min of Telazol injection and was maintained for $30 \mathrm{~min}$. Each male was subjected to $\sim 30 \mathrm{~min}$ of electrical stimulation using an AC, 60-Hz sine-wave electroejaculator (Howard et al., 1986a) and a 6-mm diameter rectal probe with 3 longitudinal electrodes. To minimize any effect of electroejaculation technique on results, the same 2 operators were always responsible for applying a highly structured semen collection protocol to each animal. After insertion of the lubricated probe into the rectum, the penis was everted, cleaned with a gauze pad and saline and then dried. The electrical stimuli were given in a 3-sec-on and 3-sec-off pattern with a continuous rise in milliamperage from 0 to the desired peak, then returning to 0 . The pattern of applied stimuli generally was consistent with previous reports (Howard et al., 1981, 1986a; Wildt et al., 1983, 1987) except that 2 additional electrical series were given. A total of 5 series of 30,30, 20,20 
and 10 stimuli were given with a 3-4-min rest period between series. Within series, sets of 10 stimuli each were applied at increasing $\mathrm{mA}$ beginning at $20 \mathrm{~mA}$. Series $2,3,4$ and 5 began with $25,50,50$ and $75 \mathrm{~mA}$, respectively. Seminal drops resulting from each series were collected from the tip of the glans penis by capillary action into a warmed $\left(37^{\circ} \mathrm{C}\right)$ glass pipette. These samples were transferred immediately into a $1 \cdot 5-\mathrm{ml}$ plastic, microcentrifuge tube (Fisher Scientific, Pittsburg, PA, USA) (in a $37^{\circ} \mathrm{C}$ waterbath) containing $120 \mu \mathrm{l}$ TEST (with or without glycerol).

At the end of electroejaculation, the volume of diluted semen was measured and, after subtracting the amount of dilution medium added, ejaculate volume was recorded. After mixing, a 2- $\mu$ l sample was placed on a glass slide under a cover slip and evaluated for sperm percentage motility and status (forward progression) using previous methods and criteria (Howard et al., 1986a, b). In brief, status was a subjective estimate of the type of forward movement of the sperm cell using a $0-5$ scale $(0=$ no movement to $5=$ steady, rapid forward progression). Each motility and status estimate was a mean value based on subjective evaluations of 10 microscopic fields $(\times 40)$ by the 2 operators. A $10-\mu l$ sample of diluted semen was used to calculate sperm concentration $/ \mathrm{ml}$ of ejaculate using a standard haemocytometer method (Wildt et al., 1983) and appropriate adjustments for the added dilution medium. The total number of motile spermatozoa/ejaculate was calculated by multiplying the sperm concentration by the ejaculate volume by the percentage motility value. A 2- $\mu$ l sample of diluted semen was fixed in 1\% glutaraldehyde for subsequent evaluation of sperm morphology (Wildt et al., 1983, 1987; Howard et al., 1986a, b). Phase-contrast microscopy ( $\times 1000)$ was used to assess morphology of 200 spermatozoa/ejaculate; cells were categorized as normal or having a bent midpiece, bent flagellum, tightly coiled flagellum, residual cytoplasmic droplet or abnormal acrosome.

Artificial insemination. Diluted ejaculates containing at least $60 \%$ motile spermatozoa and a status rating of 3 or greater were arbitrarily judged suitable for AI. At $\sim 30$ min after initial dilution with TEST, seminal samples were removed from the waterbath and maintained at room $\left(\sim 22^{\circ} \mathrm{C}\right)$ temperature. In general, the interval between dilution and insemination was $30-60 \mathrm{~min}$.

Two insemination approaches were used. In the first, 10 females treated with hCG $24 \mathrm{~h}(\mathrm{~N}=5)$ or $0 \mathrm{~h}(\mathrm{~N}=5)$ earlier were inseminated vaginally. Within each time interval, 3 of the females received semen diluted in TEST and 2 received semen diluted in TEST plus glycerol. After inducing a surgical plane of anaesthesia with Telazol $(10 \mathrm{mg} / \mathrm{kg})$ and cleaning the perineum with sterile saline, each ferret was held by the hind legs in an inverted position. Diluted semen $(100 \mu \mathrm{I})$ was aspirated into sterile polyethylene tubing (PE-50, Intramedic ${ }^{\circledR}$, Clay Adams, Parsippany, NJ, USA) which was introduced into the vaginal vault. After injecting the semen, the female was maintained in the inverted position for 10 min to prevent semen backflow. Each female was allowed to recover for $\mathrm{I} h$ before transport the same day to Path Valley Farm. Ferrets were housed separately, provided with a nest box and monitored for pregnancy.

In the second method, each female was anaesthetized with Telazol $(10 \mathrm{mg} / \mathrm{kg})$, surgically prepared and then subjected to laparoscopy using a $5 \mathrm{~mm}$ diameter, rigid laparoscope (Wildt et al., 1977; Wildt, 1980). A laparoscopic cannula assembly was inserted through a $1 \mathrm{~cm}$ skin incision made $\sim 2 \mathrm{~cm}$ anterior to the umbilicus. An abdominal pneumoperitoneum ( $5 \% \mathrm{CO}_{2}$ in air) and the use of a $2 \mathrm{~mm}$ diameter ancillary probe (inserted lateral to the midline) facilitated observation and manipulation of the reproductive tract. The ovaries could not be examined directly because of a peri-ovarian bursa and fat pad. Each uterine horn was identified and cannulated for direct deposition of semen in utero using a modification of techniques described earlier (Wildt et al., 1975; Schiewe et al., 1984). A sterile, canine indwelling catheter (Sovereign ${ }^{\circledR}$, Sherwood, St Louis, MO, USA; 18 gauge, $7 \mathrm{~cm}$ long) was inserted through the abdominal wall at a site directly ventral and caudal to the uterine horn bifurcation. The catheter was inserted into the uterine lumen of each respective horn and, upon penetrating the lumen, the stylette was withdrawn slightly within the catheter cannula and the latter advanced. Generally, the catheter was considered intraluminal when it was passed $\sim 1 \mathrm{~cm}$ and could be moved back and forth freely. Sterile, polyethylene tubing (Intramedic ${ }^{\circledR}$, PE-50) containing $50 \mu \mathrm{l}$ diluted semen was passed through the catheter. Visual movement of the uterine horn with passage of the tubing and modest ballooning of the horn immediately after insemination ensured that the semen was deposited into the proximal third of the horn. After depositing a second 50- $\mu$ l sample of semen in the contralateral horn, the catheter, tubing, laparoscope and ancillary probe were removed and the incision site sutured. Females were allowed a 1-h recovery interval and then transported immediately to Path Valley Farm. These animals were housed and monitored for pregnancy, and the number of kits produced was recorded on the morning after parturition.

Blood collection and testosterone analyses. Immediately after each electroejaculation, a blood sample ( $3 \mathrm{ml})$ was collected by jugular venepuncture from all males. After $1 \mathrm{~h}$, the sample was centrifuged $(3000 \mathrm{~g}$, $20 \mathrm{~min})$, the serum collected, stored at $-20^{\circ} \mathrm{C}$ and later analysed for testosterone. A double antibody RIA ${ }^{125}$ I kit (Radioassay Systems Inc., Carson, CA, USA) was used which employed a rabbit testosterone-19-carboxymethylether-BSA antibody with the following cross-reactivities: $100 \%$ with testosterone; $10 \cdot 3 \%$ with $5 \alpha$-dihydrotestosterone; $<1 \%$ with $5 \beta$-dihydrotestosterone, androstenedione, androstanedione, androsterone, epiandrosterone, oestrone, oestradiol-17 $\beta$, oestriol, progesterone and corticosterone. This assay has been used previously in this laboratory for other carnivore species (Wildt et al., 1987, 1988; Brown et al., 1988) and was validated for ferret serum by demonstrating recovery of mass. Upon addition of $0.05,0 \cdot 125,0 \cdot 25,0.5,1.25$ and $2.5 \mathrm{ng}$ testosterone to $25 \mu \mathrm{l}$ ferret serum, $0.08,0 \cdot 15,0.23,0 \cdot 56,0.94$ and $2.65 \mathrm{ng}$ was recovered, respectively, after subtracting endogenous hormone $(r=0.99)$. Inhibition curves for serum pools and the testosterone standard were parallel. Assay sensitivity was $0.01 \mathrm{ng} /$ tube and the inter- and intra-assay coefficients of variation were 8.5 and $7 \cdot 6 \%$, respectively.

Analysis of data. Values are reported as the mean \pm the standard error of the mean. Correlation coefficients were calculated on a preprogrammed desk-top calculator. Differences in the mean number of motile spermatozoa 
inseminated, gestation interval and litter size between groups were analysed using a Student's $t$ test, and differences in pregnancy rates were evaluated by $\chi^{2}$ analysis (Steel $\&$ Torrie, 1960).

\section{Results}

During the course of this study, male and female ferrets were anaesthetized on 291 occasions with no complications or animal deaths. Of the 250 electroejaculation attempts, $217(86.8 \%)$ were spermic and $140(56 \%)$ met our subjective AI criteria. There was wide variation in the ejaculate characteristics of males maintained in the long-day photoperiod. Males 1 and 2 produced spermic ejaculates throughout the study (Fig. 1). Of the 65 weekly electroejaculations performed in these animals, $62(95 \cdot 4 \%$, Male 1) and $65(100 \%$, Male 2) contained motile spermatozoa. For Males 1 and $2,74 \%$ and $48 \%$ of these ejaculates, respectively, were judged suitable for AI. Male 3 sporadically produced spermatozoa for 6 weeks and then produced a few structurally abnormal spermatozoa with poor motility. The number of motile spermatozoa recovered from Males 4 (Fig. 1) and 5 decreased within several weeks of being placed in the colony, remained depressed for 20-30 weeks but then improved and were comparable to levels observed in all other males.

Of the structural pleiomorphisms observed over time, the predominant abnormality was a residual cytoplasmic droplet (Fig. 2). However, the incidence of most abnormalities changed during the study, sometimes varying markedly among animals. For example, unlike any other ferret, Male 2 began producing high proportions of spermatozoa with the bent midpiece anomaly at 37 weeks (Fig. 2). As the study continued, all males gradually produced more cells with cytoplastic droplets and, at 39-46 weeks, the proportion of spermatozoa with abnormal acrosomes consistently increased from $\leqslant 1 \%$ to as high as $53 \%$ (Fig. 2).

Among all males, there were consistent correlations between certain reproductive characteristics (Table 1). Positive $(P<0.05)$ correlation coefficients were observed between sperm percentage motility and progressive status ratings, between testes volume and number of motile spermatozoa/ ejaculate and between testes volume and circulating testosterone concentrations. In general, the relationship between serum testosterone concentrations and the number of abnormal or motile spermatozoa/ejaculate either was not significant $(P>0.05)$ or differed inconsistently among males.

None of the females inseminated vaginally showed any evidence of pregnancy (mean no. of motile spermatozoa inseminated/female, $9.9 \pm 1.4 \times 10^{6}$; range, $3.6-18.5 \times 10^{6}$ ). In contrast, of the 24 ferrets inseminated laparoscopically, $17(70 \cdot 8 \%)$ became pregnant and delivered live offspring. The mean duration of gestation and litter size for these ferrets was $41.4 \pm 0.2$ days (range, 40-43) and $5 \cdot 2 \pm 0 \cdot 5$ kits (range, $2-9$ ), respectively. The mean and range of motile sperm numbers inseminated were $6.5 \pm 0.8 \times 10^{6}$ and $1.6-10.0 \times 10^{6}$ cells, respectively. There was nodifference $(P>0.05)$ in the number of motile spermatozoa deposited in vaginally-inseminated and uterine-inseminated ferrets. Likewise, the mean number of motile spermatozoa used in ferrets becoming pregnant $\left(6.2 \times 10^{6}\right)$ was not different $(P>0.05)$ from that inseminated into females which failed to become pregnant $\left(7.4 \times 10^{6}\right)$. In the laparoscopically-inseminated group, $11 / 17(64 \cdot 7 \%)$ pregnancies resulted from using $6.0 \times 10^{6}$ spermatozoa or less. Overall, the correlation between the number of motile spermatozoa inseminated and either pregnancy rate or number of young produced was low $(0 \cdot 13,0 \cdot 24$; $P>0.05)$. In one case, the ejaculate from a single male was split, diluted and inseminated laparoscopically into 2 females both of which became pregnant and delivered 7 and 6 offspring, respectively. Neither the timing of the hCG injection nor the addition of glycerol affected pregnancy rate, gestation interval or the number of young born $(P>0.05$, Table 2$)$.

\section{Discussion}

Until this study, there had been few attempts to inseminate ferrets artificially. Hammond \& Walton (1934) deposited epididymal spermatozoa into the vagina of 19 sterile-mated females but none 
(|u/bu) auodəłsolsa
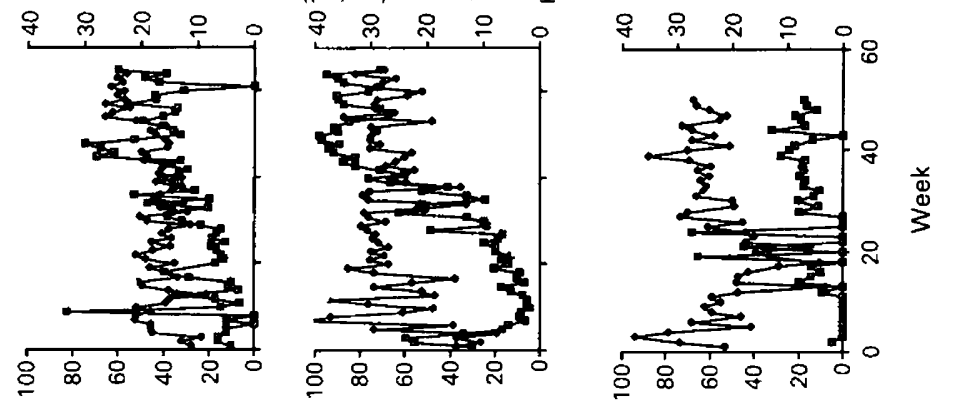

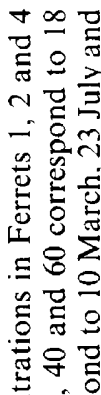

(\%) eozojeusads jeusouq
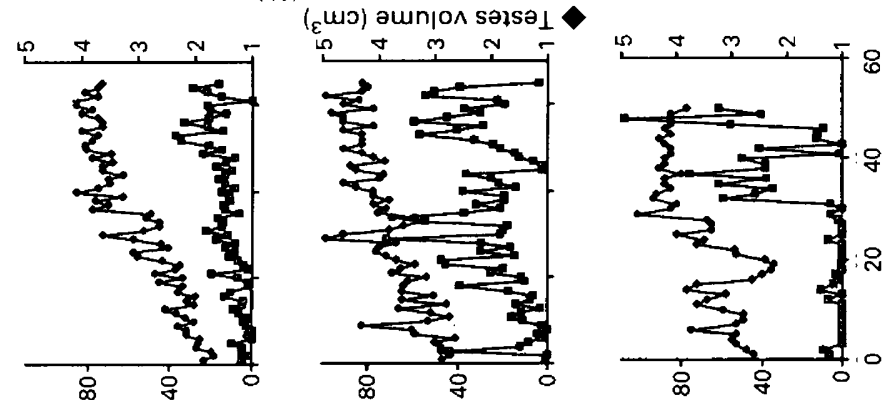

䒕施

-

8 क

过

곤

i

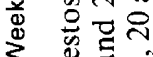

on- कs

$\Xi \approx$

$\pi$

$\overline{3} \Sigma$

능

III
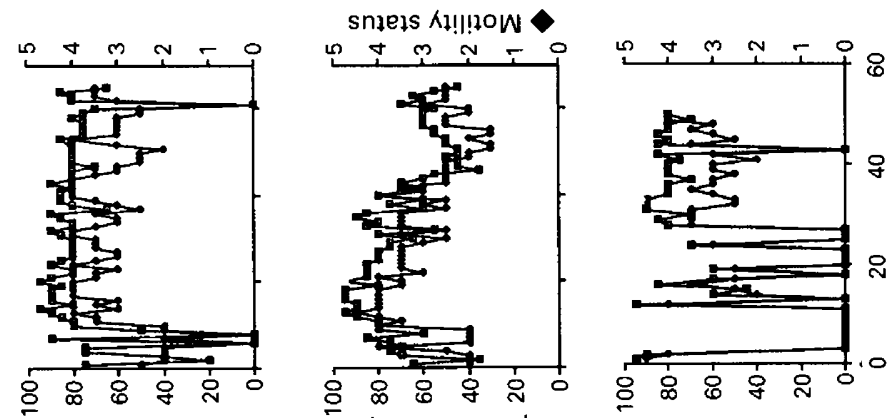

过苋

$\stackrel{\$}{ \pm}$

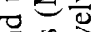

E

$\pi 8$

No 0

要

节票

के

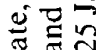

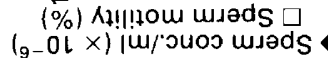
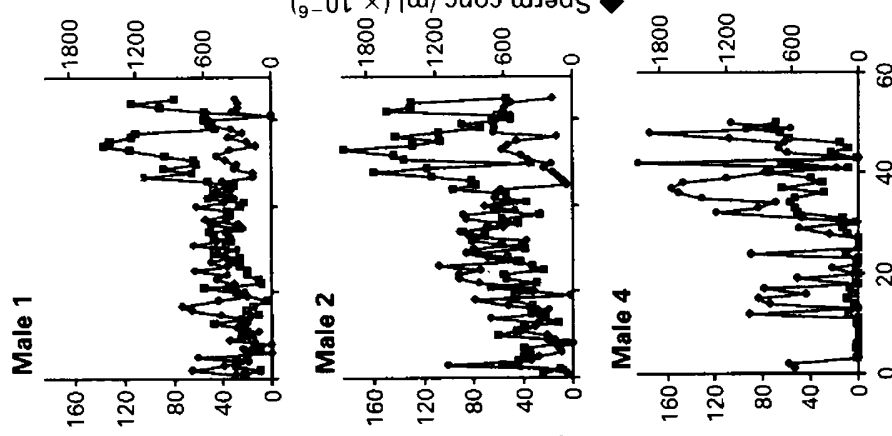

그음

苋造

ब $\frac{0}{5}$

$\Xi \sum$

话娄文

क्षे

क्ज造

\% 6 훈

可

당

$\sim$ 들

웅응

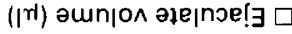



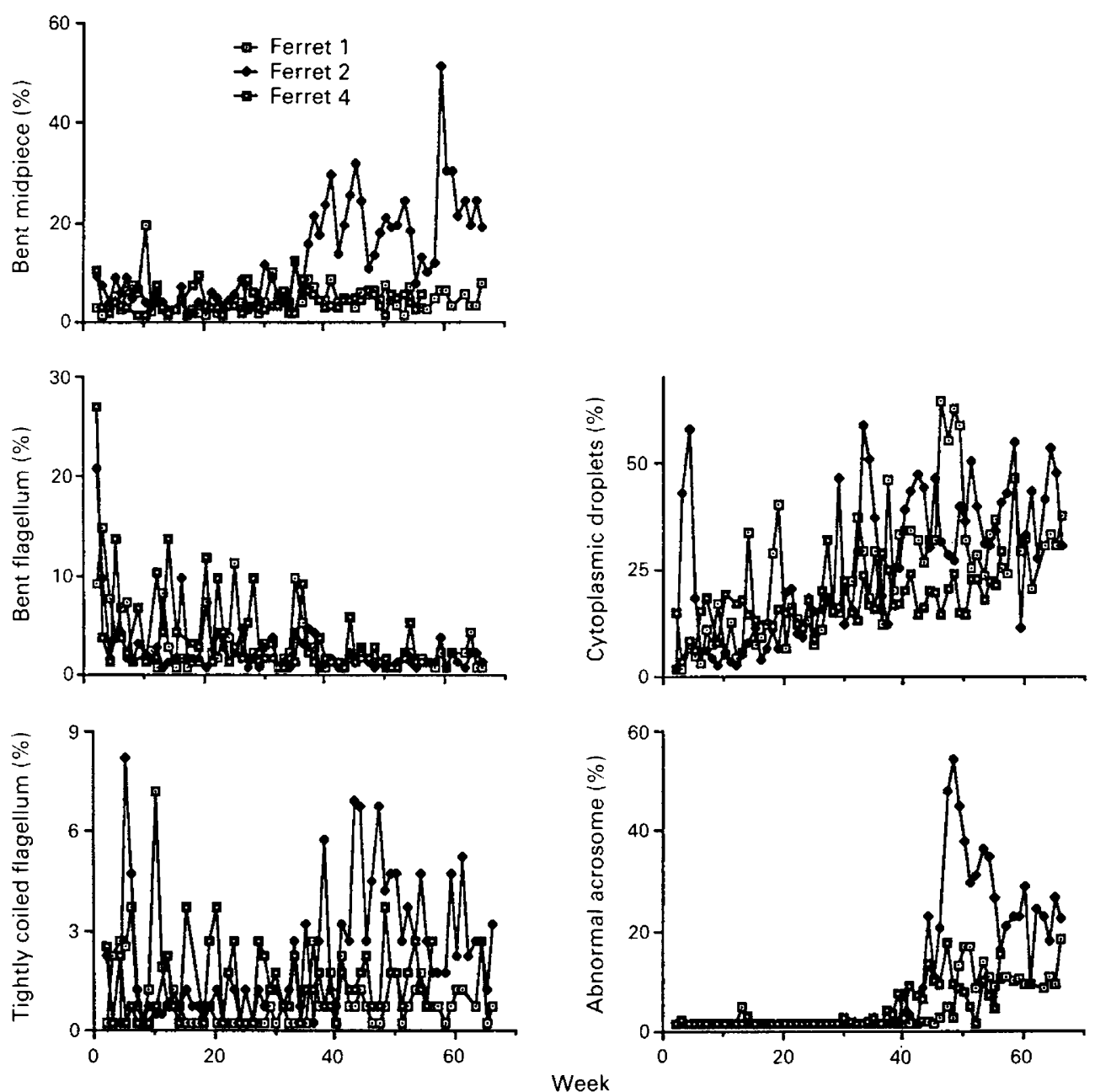

Fig. 2. Percentages of total spermatozoa with various structural abnormalities for 3 ferrets maintained under a $16 \mathrm{~h}$ light: $8 \mathrm{~h}$ dark cycle.

Table 1. Correlation coefficients between reproductive characteristics in male ferrets*

\begin{tabular}{|c|c|c|c|c|c|}
\hline & \multicolumn{5}{|c|}{ Ferret } \\
\hline & $\begin{array}{c}\text { No. } 1 \\
(\mathrm{n}=65)\end{array}$ & $\begin{array}{c}\text { No. } 2 \\
(\mathrm{n}=65)\end{array}$ & $\begin{array}{c}\text { No. } 3 \\
(\mathrm{n}=15)\end{array}$ & $\begin{array}{c}\text { No. } 4 \\
(\mathrm{n}=55)\end{array}$ & $\begin{array}{l}\text { No. } 5 \\
(\mathrm{n}=50)\end{array}$ \\
\hline Sperm motility-progressive status & $0 \cdot 82$ & 0.76 & 0.95 & 0.92 & 0.96 \\
\hline Testes volume-motile spermatozoa/ejaculate & $0 \cdot 63$ & $0 \cdot 36$ & 0.68 & 0.51 & 0.53 \\
\hline Testes volume-testosterone concentration & $0 \cdot 80$ & $0 \cdot 33$ & 0.56 & $0 \cdot 38$ & 0.43 \\
\hline $\begin{array}{l}\text { Testosterone concentration-motile spermatozoa/ } \\
\text { ejaculate }\end{array}$ & $0 \cdot 26^{\mathrm{a}}$ & $0.05^{\mathrm{a}}$ & $0 \cdot 41$ & $0 \cdot 27^{\mathrm{a}}$ & $0 \cdot 31$ \\
\hline $\begin{array}{l}\text { Testosterone concentration- } \% \text { abnormal } \\
\text { spermatozoa }\end{array}$ & $0 \cdot 13^{\mathrm{a}}$ & $-0 \cdot 01^{\mathrm{a}}$ & -0.85 & $0 \cdot 30$ & $-0 \cdot 10^{\mathrm{a}}$ \\
\hline
\end{tabular}

*Values without a superscript are significant $(P<0 \cdot 05)$. Numbers in parentheses indicate consecutive weeks that data were collected. 
Table 2. Effect of hCG injection and glycerol in sperm medium on pregnancy rate, gestation interval and number of young born in artificially inseminated ferrets

\begin{tabular}{|c|c|c|c|c|}
\hline Treatment & $\begin{array}{l}\text { Motile spermatozoa/ } \\
\text { insemination }\left(\times 10^{-6}\right)^{*}\end{array}$ & $\begin{array}{c}\text { No. pregnant } \\
(\%)\end{array}$ & $\begin{array}{l}\text { Gestation } \\
\text { (days)* }^{*}\end{array}$ & $\begin{array}{l}\text { No. of young } \\
\text { born* }\end{array}$ \\
\hline \multicolumn{5}{|l|}{$\mathrm{hCG}$} \\
\hline $24 \mathrm{~h}$ before AI & $6 \cdot 9 \pm 1 \cdot 6$ & $8 / 12(66 \cdot 7)$ & $41 \cdot 0 \pm 0 \cdot 2$ & $5.4 \pm 0.8$ \\
\hline $0 \mathrm{~h}$ before $\mathrm{AI}$ & $6.1 \pm 0.7$ & $9 / 12(75 \cdot 0)$ & $41.8 \pm 0.6$ & $5 \cdot 0 \pm 0.6$ \\
\hline \multicolumn{5}{|c|}{ Sperm dilution with TEST } \\
\hline With glycerol & $6.1 \pm 0.7$ & $9 / 12(75 \cdot 0)$ & $41 \cdot 7 \pm 0 \cdot 2$ & $5 \cdot 0 \pm 0 \cdot 6$ \\
\hline Without glycerol & $6.9 \pm 1 \cdot 6$ & $8 / 12(66 \cdot 7)$ & $41 \cdot 1 \pm 0 \cdot 2$ & $5.4 \pm 0.7$ \\
\hline
\end{tabular}

*Values are mean \pm s.e.m.

became pregnant. Chang (1965), conducting elegant work on the fertilizable life-span of ferret spermatozoa, injected epididymal spermatozoa into the uterine lumen of laparotomized, hCGtreated females and produced 3 litters. Carpenter \& Hillman (1978), using a similar approach but electroejaculated semen, inseminated 2 domestic ferrets and produced a single litter. Our study confirmed that vaginal Al was an ineffective method of artificially breeding ferrets. However, laparoscopic insemination in utero offered a relatively atraumatic approach for achieving high pregnancy rates. Because all females were handled and hormonally-treated in the same fashion, it must be inferred that pregnancy failure in the vaginal insemination group was associated with an unsuitable vaginal environment or poor sperm transport through the cervix and caudal aspects of the uterine horns.

Chang (1965) demonstrated that ferret spermatozoa retain their fertilizing capacity in the female tract for as long as $126 \mathrm{~h}$. Because this interval is much longer than for most domesticated species, Chang (1965) contended that this unique feature was closely associated with the ferret's evolution as an induced ovulator (i.e. spermatozoa deposited at mating must remain viable until ovulation). Our results supported these assertions as there was no difference in pregnancy rates of in-utero inseminated ferrets given hCG 0 or $24 \mathrm{~h}$ before scheduled insemination. Assuming that ovulation occurred 24-36 h after hCG (Chang \& Yanagimachi, 1963; Chang, 1965), then spermatozoa deposited at the time of gonadotrophin injection were sustained for 1 or more days before participating in fertilization. This finding has particular relevance to the practical application of AI to ferrets because a female given hCG is committed, inevitably, to ovulation (Chang, 1965). If AI is scheduled and for some reason semen was not recovered from a male and no frozen spermatozoa were in reserve, then an hCG pre-treated female would be induced into a sterile luteal phase (pseudopregnancy) (Blatchley \& Donovan, 1976) and lost for the breeding season. The present results indicated that the commitment to hCG-induced ovulation is unnecessary until a suitable quality ejaculate is available for use. If a female was injected with hCG, then AI could be conducted for up to $24 \mathrm{~h}$ after treatment with a high likelihood for success.

The pregnancy range of 40-43 days in laparoscopically-inseminated ferrets was similar to the gestation interval of naturally-mated females maintained under normal production conditions at Path Valley Farm. However, this commercial operation routinely observes litter sizes of 6-12 kits after natural breeding which is more than the average litter size of $5 \cdot 2$ observed after AI. The exact cause for this reduced litter size is unknown. The prolonged longevity of ferret spermatozoa in utero argues against a sperm or egg ageing problem. An inadequate ovulatory response to hCG also is unlikely as Chang (1965) reported that this same dose used in the ferret causes an average release of 14.5 eggs/female (range, 8-24). Additionally, although Chang (1965) suggested that fertility is higher in ferrets inseminated with more spermatozoa, we found no evidence that sperm number affected pregnancy rate or litter size. Although the minimum sperm number required to achieve pregnancy after AI in utero was not determined, conceptions occurred using as few as $1.6 \times 10^{6}$ spermatozoa. In one case, a split ejaculate from a single 
male was used to produce 2 pregnancies and a total of 13 kits. Because $54 \%$ of all spermic electroejaculates contained at least $10 \times 10^{6}$ motile spermatozoa or more, in theory, a single ejaculate could be used to service numerous females, or seminal samples could be frozen-stored for later use. Although a successful frozen semen technique has not been reported for the ferret, the common sperm cryoprotectant, glycerol, mixed with the dilution medium had no detrimental effects on sperm viability. Pregnancy rates and offspring numbers were similar between glycerolated and non-glycerolated treatment groups.

Reproductive behaviour and vaginal cytology characteristics in domestic and black-footed ferrets are quite similar (Carpenter, 1977; Carpenter \& Hillman, 1978). It is common for male domestic ferrets to be sexually active at least 1 month before females, and, likewise, unmated females often exhibit oestrus 1 or more months after males become sexually reactivated (Allanson, 1932; Neal et al., 1977). Efforts to breed black-footed ferrets during 1987 and 1988 have revealed a similar asynchronous pattern, particularly in younger females which tend to exhibit oestrus later in the season (E. T. Thorne \& B. Williams, personal communication). Artificially extending the reproductive season of male ferrets would ensure the availability of fertile males throughout the breeding season and improve the opportunity for collecting and freezing semen for later artificial insemination use. The present results demonstrated that domestic ferrets maintained chronically in a 16L: 8D cycle were capable of producing spermic ejaculates for as long as 65 consecutive weeks. However, only a portion of the males were capable of sustained spermatogenesis and, as the study progressed, the quality of the semen did not always meet the minimal subjective criteria for AI. It also was apparent that, although a prolonged $16 \mathrm{~L}: 8 \mathrm{D}$ photoperiod extended sperm production and testis size in certain males, the structural integrity of the cells became compromised over time. The consistent finding of more immature spermatozoa as the study progressed suggested that the once weekly semen recovery procedure was depleting epididymal reserves and prohibiting normal maturational events. Of more significance was the consistent observation of a direct relationship between the length of time on the artificial photoperiod and the proportion of spermatozoa with severely deformed acrosomes. The increase in pleiomorphisms appeared independent of either testicular volume or circulating testosterone concentrations.

During the mating season, circulating testosterone concentrations in domestic male ferrets fluctuate from 26 to $60 \mathrm{ng} / \mathrm{ml}$ but decrease below $5 \mathrm{ng} / \mathrm{ml}$ during periods of sexual inactivity (Neal et al., 1977; Erskine \& Baum, 1982). Using these values as general criteria and even accounting for differences in RIA systems, then ferrets in the present study nearly always produced testosterone levels indicative of gonadal androgen production. Of the 250 total blood samples, $223(89 \cdot 2 \%)$ contained at least $12 \mathrm{ng}$ testosterone/ml, a level more than 2 -fold greater than the basal concentrations reported by Neal et al. (1977) and Erskine \& Baum (1982). Although the long-day photoperiod sustained high serum testosterone concentrations in the ferret throughout the study, this did not always ensure that the ejaculates were either spermic or contained high quality spermatozoa. Therefore, although other non-androgenic mechanisms may play a vital role in ensuring sperm production and structural integrity in the ferret, it would appear appropriate to examine the interrelationship between gonadotrophins and testicular androgens. In male ferrets maintained under a similar light:dark cycle both luteinizing hormone and testosterone were secreted in a pulsatile fashion, but hormonal amplitude and pulse frequency were quite variable amongst individual males (Sisk \& Desjardins, 1986). Perhaps the inter-animal variability observed in the latter study was related to our observations of male differences in sperm production in ferrets maintained chronically under an artificially long photoperiod. Nevertheless, the high correlation between testicular volume and serum testosterone found among ferrets in our colony was similar to that reported for ferrets housed outside and exposed to natural fluctuations in photoperiod (Neal et al., 1977). Although serum testosterone was a poor indicator of the number of motile spermatozoa/ ejaculate, testicular volume was correlated to this sperm production index (Table 1), as reported for the bull (Coulter \& Foote, 1979), Dorcas gazelle (Howard et al., 1983), red deer stag (Haigh et al., 1984) and human (Sherins \& Howards, 1985). 
In summary, these results demonstrate the high efficiency of artificial breeding of domestic ferrets when ejaculated spermatozoa are deposited in utero by a transabdominal laparoscopic approach. The natural longevity of ferret spermatozoa in utero allows AI to be performed coincident with hCG treatment and before ovulation without compromising subsequent fertility. Although a daily 16 -h photoperiod was ineffective for sustaining spermatogenesis in all ferrets, 2 males produced ejaculates meeting AI criteria for 20 and 26 consecutive weeks, respectively. This suggests that such an approach applied to a group of sperm donors probably would ensure the availability of at least some reproductively competent male ferrets throughout the female's extended breeding season.

We thank Dr J. L. Brown (Uniformed Services University) for validating the testosterone RIA; Dr E. F. Graham (University of Minnesota) for supplying the TEST diluent; and Dr K. Goodrowe, T. Cummings, S. Hurlbut (National Zoological Park), Dr U. S. Seal and Dr R. Mead (Captive Breeding Specialist Group), Dr E. T. Thorne (Wyoming Department of Fish and Game), Dr R. Atherton and Dr B. Williams (University of Wyoming) and the staff of the National Institutes of Health Animal Center and Path Valley Farm for assisting with various aspects of this study. This research was funded by grants from the U.S. Fish \& Wildlife Service (National Ecology Center), the Friends of the National Zoo, the Women's Committee of the Smithsonian Associates and the Mars Foundation.

\section{References}

Allanson, M. (1932) The reproductive processes of certain mammals. III. The reproductive cycle of the male ferret. Proc. R. Soc. Lond. B 110, 295-314.

Baum, M.J. \& Goldfoot, D.A. (1974) Effect of hypothalamic lesions on maturation and annual cyclicity of the ferret testis. J. Endocr. 62, 59-73.

Bissonette, T.H. (1932) Modification of mammalian sexual cycles; reactions of ferrets (Putorius vulgaris) of both sexes to electric light added after dark in November and December. Proc. R. Soc. Lond. B 110, $322-326$.

Bissonette, T.H. (1935) Modification of mammalian sexual cycles. IV. Delay of oestrus and induction of anoestrus in female ferrets by reduction of intensity and duration of daily light periods in the normal oestrus season. J. exp. Biol. 12, 315-320.

Black-Footed Ferret Recovery Plan (1988) U.S. Fish \& Wildlife Service, Denver, CO, 154 pp.

Blatchley, F.R. \& Donovan, B.T. (1976) Progesterone secretion during pregnancy and pseudopregnancy in the ferret. $J$. Reprod. Fert. 46, 455-456.

Brown, J.L., Goodrowe, K.L., Simmons, L.G., Armstrong, D.L. \& Wildt, D.E. (1988) Evaluation of the pituitarygonadal response to $\mathrm{GnRH}$, and adrenal status, in the leopard (Panthera pardus japonensis) and tiger (Panthera tigris). J. Reprod. Fert. 82, 227-236.

Carpenter, J.W. (1977) Propagation and management of endangered species at the Patuxent Wildlife Research Center. Proc. Am. Assoc. Zoo Vet. pp. 23-33.

Carpenter, J.W. \& Hillman, C.N. (1978) Husbandry, reproduction and veterinary care of captive ferrets. Proc. Am. Assoc. Zoo Vet. pp. 36-47.

Carroll, R.S., Erskine, M.S., Doherty, P.C., Lundell, L.A. \& Baum, M.J. (1985) Coital stimuli controlling luteinizing hormone secretion and ovulation in the female ferret. Biol. Reprod. 32, 925-933.
Carroll, R.L., Erskine, M.S. \& Baum, M.J. (1987) Sex difference in the effect of mating on the pulsatile secretion of luteinizing hormone in a reflex ovulator, the ferret. Endocrinology 121, 1349-1359.

Chang, M.C. (1965) Fertilizing life of ferret sperm in the female tract. J. exp. Zool. 158, 87-100.

Chang, M.C. (1968) Reciprocal insemination and egg transfer between ferrets and mink. J. exp. Zool. 168, 49-60.

Chang, M.C. \& Yanagimachi, R. (1963) Fertilization of ferret ova by deposition of epididymal sperm into the ovarian capsule with special reference to the fertilizable life of ova and the capacitation of sperm. J. exp. Zool. 154, 175-188.

Clark, T.W. (1987) Black-footed ferret recovery: a progress report. Conserv. Biol. 1, 8-11.

Coulter, G.H. \& Foote, R.H. (1979) Bovine testicular measurements as indicators of reproductive performance and their relationship to reproductive traits in cattle. A review. Theriogenology 11, 297-311.

Donovan, B.T. (1967) The effect of light upon reproductive mechanisms, as illustrated by the ferret. In Effects of External Stimuli on Reproduction (Ciba Fdn Study Group No. 26), pp. 43-52. Churchill, London.

Erskine, M.S. \& Baum, M.J. (1982) Plasma concentrations of testosterone and dihydrotestosterone during peri-natal development in male and female ferrets. Endocrinology 111, 767-772.

Hammond, J. \& Marshall, F.H.A. (1930) Oestrus and pseudopregnancy in the ferret. Proc. R. Soc. Lond. B $105,607-638$.

Hammond, J. \& Walton, A. (1934) Notes on ovulation and fertilization in the ferret. $J$. exp. Biol. 11, 307-319.

Haigh, J.C., Cates, W.F., Glover, G.J. \& Rawlings, N.C. (1984) Relationships between seasonal changes in 
serum testosterone concentrations, scrotal circumference and sperm morphology of male wapiti (Cervus elaphas). J. Reprod. Fert. 70, 413-418.

Herbert, J., Stacey, P.M. \& Thorpe, D.H. (1978) Recurrent breeding seasons in pinealectomized or opticnerve-sectioned ferrets. J. Endocr. 78, 389-397.

Howard, J.G., Pursel, V.G., Wildt, D.E. \& Bush, M. (198I) Comparison of various extenders for freeze preservation of semen from selected captive wild ungulates. J. Am. vet. med. Assoc. 179, 1157-1161.

Howard, J.G., Wildt, D.E., Chakraborty, P.K. \& Bush, M. (1983) Reproductive traits including seasonal observations on semen quality and serum hormone concentrations in the Dorcas gazelle. Theriogenology 20, $221-229$.

Howard, J.G., Bush, M. \& Wildt, D.E. (1986a) Semen collection, analysis and cryopreservation in nondomestic mammals. In Current Therapy in Theriogenology, pp. 1047-1053. Ed. D. Morrow. W.B. Saunders Co., Philadelphia.

Howard, J.G., Bush, M., de Vos, V., Schiewe, M.C., Pursel, V.G. \& Wildt, D.E. (1986b) Influence of cryoprotective diluent on post-thaw viability and acrosomal integrity of spermatozoa from the African elephant (Loxodonta africana). J. Reprod. Fert. 78, 295-306.

Neal, J., Murphy, B.D., Moger, W.H. \& Oliphant, L.W. (1977) Reproduction in the male ferret: gonadal activity during the annual cycle; Recrudescence and maturation. Biol. Reprod. 17, 380-385.

O'Brien, S.J., Martenson, J.S., Eichelberger, M.A., Thorne, E.T. \& Wright, F. (1989) Biochemical genetic variation and molecular systematics of the blackfooted ferret, Mustela nigripes. In Conservation Biology and the Black-Footed Ferret (in press). Eds. U. S. Seal, E. T. Thorne, M. A. Bogan \& S. H. Anderson. Yale University Press, New Haven.

Robinson, A. (1918) The formation, rupture and closure of ovarian follicles in ferrets and ferret-polecat hybrids and some associated phenomena. Trans. Roy. Soc. Edinb. 52, 303-362.

Ryan, K.D. (1984) Hormonal correlates of photoperiodinduced puberty in a reflex ovulator, the female ferret (Mustela furo). J. Reprod. Fert. 31, 925-935.

Ryan, K.D. \& Robinson, S.L. (1987) A study of spontaneous sexual maturation of the female ferret. Biol. Reprod. 36, 333-339.
Schiewe, M.C., Bush, M., Stuart, L.S. \& Wildt, D.E. (1984) Laparoscopic embryo transfer in domestic sheep: a preliminary study. Theriogenology 22, 675-682.

Sherins, R.J. \& Howards, S.S. (1985) Male infertility. In Campbell's Urology, 5th Edition, pp. 640-697. Eds P. C. Walsh, R. E. Gittes, A. D. Perlmutter \& T. A. Stamey. W.B. Saunders Co., Philadelphia.

Sisk, C. (1987) Evidence that a decrease in testosterone negative feedback mediates the pubertal increase in luteinizing hormone pulse frequency in male ferrets. Biol. Reprod. 37, 73-81.

Sisk, C.L. \& Desjardins, C. (1986) Pulsatile release of luteinizing hormone and testosterone in male ferrets. Endocrinology 119, 1195-1203.

Steel, R.G.D. \& Torrie, J.H. (1960) Principles and Procedures of Statistics. McGraw-Hill, New York.

Wildt, D.E. (1980) Laparoscopy in the dog and cat. In Animal Laparoscopy, pp. 31-72. Eds R. M. Harrison \& D. E. Wildt. Williams \& Wilkins, Baltimore.

Wildt, D.E., Morcom, C.B. \& Dukelow, W.R. (1975) Laparoscopic pregnancy diagnosis and uterine fluid recovery in swine. $J$. Reprod. Fert. 44, 301-304.

Wildt, D.E., Kinney, G.M. \& Seager, S.W.J. (1977) Laparoscopy for direct observation of internal organs of the domestic cat and dog. Am. J. vet. Res. 38, 1429-1432.

Wildt, D.E., Bush, M., Howard, J.G., O'Brien, S.J., Meltzer, D., van Dyk, A., Ebedes, H. \& Brand, D.J. (1983) Unique seminal quality in the South African cheetah and a comparative evaluation in the domestic cat. Biol. Reprod. 29, 1019-1025.

Wildt, D.E., Bush, M., Goodrowe, K.L., Packer, C., Pusey, A.E., Brown, J.L., Joslin, P. \& O'Brien, S.J. (1987) Reproductive and genetic consequences of founding isolated lion populations. Nature, Lond. 329, 328-331.

Wildt, D.E., Phillips, L.P., Simmons, L.G., Chakraborty, P.K., Brown, J.L., Howard, J.G., Teare, A. \& Bush, M. (1988) A comparative analysis of ejaculate and hormonal characteristics of the captive male cheetah, tiger, leopard and puma. Biol. Reprod. 38, 245-255.

Received 27 September 1988 